\title{
TIMI Coronary Thrombus Grade 3
}

National Cancer Institute

\section{Source}

National Cancer Institute. TIMI Coronary Thrombus Grade 3. NCI Thesaurus. Code C119585.

Moderate size definite thrombus, with greatest linear dimension greater than 1/2 but less than 2 vessel diameters. (Gibson, C. M., de Lemos, J. A., Murphy, S. A., Marble, S. J., McCabe, C. H., Cannon, C. P., Antman, E. M., Braunwald, E. Combination therapy with abciximab reduces angiographically evident thrombus in acute myocardial infarction: a TIMI 14 substudy Circulation. 2001;103(21):2550-4.) 